\title{
Plasma Cholesterol and Lathosterol Levels in Term Infants in the Early Neonatal Period
}

\author{
J. J. HAMILTON, A. SYNNES, AND S. M. INNIS \\ Department of Pathology [J.J.H.] and Department of Pediatrics [A.S., S.M.I], University of British Columbia and \\ British Columbia Children's Hospital, Vancouver, British Columbia, Canada V5Z $4 \mathrm{H} 4$
}

\begin{abstract}
Plasma cholesterol concentrations increase after birth. Whether this is due to increased cholesterol synthesis has not been reported. Additionally, it is not known if formulas, which lack cholesterol, result in higher rates of cholesterol synthesis than feeding breast milk. To address this, plasma lathosterol (quantitated by gas chromatography), a potential indicator of cholesterol synthesis, was measured in term infants at birth (cord) and $4 \mathrm{~d}$ of age fed either formula or breast milk ( $n=6$ each), normal adults $(n=6)$ at the expected nadir and peak of the diurnal rhythm $(1700 \mathrm{~h}$ and $0830 \mathrm{~h})$, and cholestyramine-treated hypercholesterolemic adults $(n=6)$. Plasma cholesterol and apo $B$ increased, and apo AI (measured by immunoprecipitation) did not change over the first $4 \mathrm{~d}$ of life. The increase in plasma cholesterol was greater in the formulafed infants compared with breast-fed infants. The plasma lathosterol concentrations $(\mu \mathrm{mol} / \mathrm{L})$ and the lathosterol:cholesterol ratios $\left(10^{2} \times \mathrm{mmol}\right.$ lathosterol $/ \mathrm{mol}$ cholesterol) decreased from birth to $4 \mathrm{~d}$ of age by 12 and $36 \%$, respectively, in the breast-fed infants and by 20 and $46 \%$, respectively, in formula-fed infants. The infant plasma lathosterol concentrations, however, were not different from normal adult levels $[1700 \mathrm{~h}: 5.50 \pm 1.52$ (SD); 0830 h: $6.18 \pm 1.80$, but were lower than those of cholestyramine-treated adults $(20.48 \pm 13.41)$. Sterol ratios of infants were higher than those of normal adults $(1700 \mathrm{~h}: 112.5 \pm$ $26.0 ; 0830 \mathrm{h:} 129.4 \pm 42.2$ ), but not different from those of cholestyramine-treated adults $(322.9 \pm 168.4)$. These data show that the evaluation in plasma cholesterol between birth and $d 4$ of age is not accompanied by increased plasma lathosterol levels, suggesting no increase in cholesterol synthesis. Further, infants fed formula do not have greater plasma lathosterol levels than breast-fed infants. (Pediatr Res 31: 396-400, 1992)
\end{abstract}

\section{Abbreviations}

HMG CoA, 3-hydroxy-3-methylglutaryl coenzyme A glc, gas-liquid chromatography

In several mammalian species studied, plasma cholesterol levels increase after birth and fall at the approximate time of weaning (1-4). Humans, too, exhibit a postnatal increase in plasma cholesterol levels, and work by Potter (5) shows that this

Received April 11, 1991; accepted November 22, 1991.

Correspondence and reprint requests: S. M. Innis, Ph.D., Department of Pediatrics, University of British Columbia, Rm 179, Research Centre, 950 W. 28th Ave., Vancouver, B.C., Canada V5Z $4 \mathrm{H} 4$.

Supported by a grant from the British Columbia Medical Services Foundation $\mathrm{J}$. J. H. is the recipient of a British Columbia Children's Hospital Research Division Studentship. S. M. I. is supported as a Career Investigator of the British Columbia Children's Hospital. occurs by $5 \mathrm{~d}$ postpartum. Thereafter, plasma cholesterol levels continue to increase until 3-4 y of age, decrease at adolescence, and then again rise slowly throughout life (6). Several hypotheses have been offered to explain the early postnatal increase in plasma cholesterol. These include the start of oral feeding (7-9), change(s) in hormonal milieu $(8,9)$, a decrease in LDL receptor number (10), and reduced adrenal uptake of lipoproteins (11).

One possible mechanism for the postnatal elevation of plasma cholesterol is increased cholesterol synthesis. Studies in the rat, however, have shown that cholesterol synthesis, as measured by the hepatic activity of the rate-limiting enzyme HMG CoA reductase (EC 1.1.1.34), decreases after birth (12), and some evidence of possible cholesterol synthesis inhibitors in milk have been published $(12,13)$. These data have been extrapolated to humans (5) to suggest that this is a universal postnatal phenomenon, but to the best of our knowledge cholesterol synthesis has been measured in only the human fetus $(14,15)$, not the newborn.

Cholesterol synthesis is commonly assessed in vitro by assay of the activity of $\mathrm{HMG} \mathrm{CoA}$ reductase (16). Alternative methods more appropriate for the human, which do not require liver biopsy, are based on incorporation of deuterated water into cholesterol (17) or assay of plasma mevalonate (18). These involve inappropriately large blood samples for newborn studies and/or laborious methodology. Farkkila and Miettinen (19) have described a method for assessment of cholesterol synthesis in vivo by direct assay of serum sterol using glc. Quantities of lathosterol (free and esterified), a sterol precursor of cholesterol, are correlated with the activity of hepatic $\mathrm{HMG} \mathrm{CoA}$ reductase in human liver (20) and with whole-body cholesterol synthesis as measured by balance studies (21). It is thought that total lathosterol leaks from the cell into the plasma at a rate proportional to the synthesis of cholesterol (21). Lathosterol is present in plasma at concentrations 1000 -fold less than cholesterol.

The objective of this study was to determine whether or not the postnatal elevation in plasma cholesterol levels is coincident with enhanced cholesterol synthesis, as indicated by plasma lathosterol levels. Plasma lathosterol concentrations were determined in term infants at birth and $4 \mathrm{~d}$ of age. Infants fed breast milk and formula have comparable plasma cholesterol levels during the first week of life (22), breast milk providing approximately $20 \mathrm{mg} / \mathrm{dL}$ cholesterol (23) and formula containing no cholesterol. Therefore, these studies also determined whether or not additional cholesterol synthesis, as indicated by plasma cholesterol, was required to maintain plasma cholesterol levels in infants fed formula.

\section{MATERIALS AND METHODS}

Infants. Twelve single-birth term infants born by elective cesarean section at Grace Hospital, Vancouver, B.C., were recruited for this study. This population, chosen to avoid possible effects of labor and delivery on cord plasma cholesterol levels $(5,24-$ 26 ), had a mean gestational age of $38.7 \pm 0.8$ (SD) wk and birth 
weight of $3372 \pm 440 \mathrm{~g}$. None of the mothers had diabetes of any origin or hypertension, and all infants were apparently medically and metabolically normal. The mother's choice to breast-feed or use infant formula was made freely without the advice of anyone involved in this study. The infants were fed ad libitum at approximately 3-h intervals, and their weight was recorded daily. Six of the infants were fed exclusively with formula; five were fed only Enfalac (Mead Johnson, Belleville, Ontario, Canada), and one infant was fed Enfalac for $48 \mathrm{~h}$ and then Prosoybee (Mead Johnson). The other six infants were breast-fed; three infants had one to five supplementary feedings of Enfalac (totalling 20,60, and $140 \mathrm{~mL}$ ) during the first $48 \mathrm{~h}$. All of the breast-fed infants were Caucasian, and, of the infants fed formula, one was Caucasian and five were Oriental. There were equal numbers of males and females in each group.

Blood Collection. At birth, the umbilical cord was clamped and blood $(1 \mathrm{~mL})$ was collected by puncture of the umbilical vein within $2 \mathrm{~min}$ of delivery. Blood $(0.5 \mathrm{~mL})$ was sampled at 4 $\mathrm{d}$ of age $(92-103 \mathrm{~h}$, between 0815 and $1545 \mathrm{~h}$ ) by venipuncture of a vein on the dorsum of the hand. Plasma was obtained after centrifugation at $3000 \mathrm{rpm}, 15 \mathrm{~min}, 4^{\circ} \mathrm{C}$, and stored frozen at $-70^{\circ} \mathrm{C}$ within $4 \mathrm{~h}$ of collection.

Adult Reference Populations. Normal, healthy, Caucasian male adults were recruited for this study if they met the following criteria: they were nonsmokers, had no history of heart disease, were not taking medications, were not drinking more than four cups of coffee/d, were within 1 SD of their ideal body weight, and ate a typical North American diet as verified by a 24-h food intake record. The final six participants had a mean age of 29.3 $\pm 3.8(\mathrm{SD}) \mathrm{y}$, weighed $69.2 \pm 9.3 \mathrm{~kg}$, and were $179.2 \pm 7.1 \mathrm{~cm}$ tall. Blood was sampled by venipuncture before meals at $1700 \mathrm{~h}$ $( \pm 25 \mathrm{~min})$ and $0830 \mathrm{~h}( \pm 20 \mathrm{~min})$ the next morning. These sampling times represent the nadir and peak, respectively, of the cholesterol synthesis diurnal cycle as measured by deuterium incorporation (17). Plasma was prepared and stored as described above.

Blood was sampled by venipuncture $(0500$ and $1000 \mathrm{~h})$, from six familial hypercholesterolemia patients from the Lipid Clinic of University Hospital, Shaughnessy Site, Vancouver, B.C. Patients were undergoing p.o. therapy with cholestyramine resin (Questran; Bristol Laboratories, Belleville, Ontario, Canada), a bile acid sequestrant known to increase cholesterol synthesis and plasma lathosterol concentrations $(20,27)$. The patients included two women and four men ranging in age from 16 to $72 \mathrm{y}$. The dose of cholestyramine resin ranged from 4 to $16 \mathrm{~g} / \mathrm{d}$ over a duration of 1-5 y, affecting a reduction of plasma LDL-cholesterol levels of 1.5-2.6 mmol/L. All plasma samples were prepared and stored as above.

Sterol Analyses. Plasma cholesterol levels were determined using an enzymatic kit (Diagnostic Chemicals, Ltd., Charlottetown, Prince Edward Island, Canada), and quality control serum (Sigma Chemical Co., St. Louis, MO) was included in each assay. The interassay coefficient of variation was $<2 \%$. Plasma lathosterol was extracted (19) and quantitated by glc (20) as previously described with minor modification. In brief, $5 \alpha$-cholestane (internal standard, Sigma Chemical Co.) was added to $50-100 \mu \mathrm{L}$ of plasma and saponified with $50 \% \mathrm{KOH}$ and methanol $(6: 94$, $\mathrm{vol} / \mathrm{vol}$ ) for $1 \mathrm{~h}$ at $80^{\circ} \mathrm{C}$. This was extracted three times with petroleum ether, dried, and silylated with hexamethyldisilane:trimethylchlorosilane: dimethylformamide, 20:2:5 vol/vol/ vol (Pierce, Rockford, IL), for $5 \mathrm{~min}$ at room temperature. The sterols were then injected into a Varian (Varian Canada Ltd., Georgetown, Ontario, Canada) 3400 glc equipped with flame ionization detection and a Varian 401 data system. Separation was achieved on an RTx-1, $25 \mathrm{~m}$ capillary column, $0.25 \mathrm{~mm}$ internal diameter, $0.25 \mu \mathrm{m}$ thickness (Restek Corp., Bellefonte, PA). Samples were injected at $80^{\circ} \mathrm{C}$, and, after remaining at this temperature for $1 \mathrm{~min}$, the oven temperature was programmed to increase to $120^{\circ} \mathrm{C}\left(20^{\circ} \mathrm{C} / \mathrm{min}\right)$, hold for $7 \mathrm{~min}$, rise to $249^{\circ} \mathrm{C}$ $\left(20^{\circ} \mathrm{C} / \mathrm{min}\right)$, hold for $15 \mathrm{~min}$, rise to $269^{\circ} \mathrm{C}\left(20^{\circ} \mathrm{C} / \mathrm{min}\right)$, and hold for $20 \mathrm{~min}$. The oven was then heated to $320^{\circ} \mathrm{C}\left(20^{\circ} \mathrm{C} / \mathrm{min}\right)$ for $5 \mathrm{~min}$ before subsequent analyses. The injector and detector were set at $300^{\circ} \mathrm{C}$ and $320^{\circ} \mathrm{C}$, respectively. The carrier gas (helium) flow rate was $1.25 \mathrm{~mL} / \mathrm{min}$ with the inlet splitter set at $100: 1$ and the relays programmed to come on at $0.7 \mathrm{~min}$ after the run start.

Lathosterol peak identification was confirmed using an authentic standard (Sigma Chemical Co.). The interassay coefficient of variation was $11 \%$. As done previously (19), lathosterol was reported as $\mu \mathrm{mol} / \mathrm{L}$ and as the ratio of lathosterol:cholesterol $\left(10^{2} \times \mathrm{mmol}\right.$ lathosterol $/ \mathrm{mol}$ cholesterol).

Apolipoprotein Analyses. Plasma apo AI and B were measured in the frozen plasma samples by immunoprecipitation (Beckman Array Protein System, Palo Alto, CA). The interassay coefficient of variation was $\leq 8 \%$ for both assays.

Statistical Analysis. Infants. Group and time effects and their joint effect on the data were examined using a multivariate analytic approach [Roy's greatest root (28)] to the repeated measures design. When there was evidence of an interaction between group and time on an effect, group effects were examined separately at each time using $t$ tests and, similarly, paired $t$ tests were used to examine the time effects for each group.

Adults. One-sided, paired $t$ tests were used to compare normal adult data at 1700 and $0830 \mathrm{~h}$. A series of two-sided $t$ tests were used to compare infant with normal adult values, and one-sided $t$ tests were used to compare both infant and normal adult values with cholestyramine-treated patient data.

Ethics. Study protocol was approved by the clinical screening committees for research and other studies involving human subjects of the University of British Columbia, British Columbia Children's and Grace Hospitals. Informed consent was obtained from all volunteers and parents to allow their infant's participation.

\section{RESULTS AND DISCUSSION}

Plasma cholesterol and apolipoproteins. The increase in plasma cholesterol levels by approximately $40 \%$ over the first $4 \mathrm{~d}$ of life found in this study (Table 1) is consistent with the results of others $(5,9,22,29)$. However, the higher cholesterol levels in both cord and d- 4 plasma of the formula group than in the breast milk group ( $p=0.05$ ) differ from previous reports of no differences at $3 \mathrm{~d}(22)$ and $5 \mathrm{~d}(5)$ of life. Separate statistical analyses of the cord plasma cholesterol revealed no significant racial differences $(p=0.71)$. We, along with others (30), have observed that by $6 \mathrm{wk}$ of age breast-fed infants have higher plasma cholesterol levels than their counterparts fed formula (unpublished observations).

Results of the apolipoprotein analyses indicate that the rise in cholesterol level was associated with VLDL and LDL rather than HDL. Others $(9,29)$ have reported that cholesterol is fairly equally distributed between HDL and LDL in cord blood, but after birth LDL predominates. In agreement with previous findings, we found (Table 1) no change in apo AI concentrations between cord and d-4 samples $(5,9,22,29)$ but an increase of approximately $66 \%$ in apo B levels $(9,22,29)$.

Plasma lathosterol concentrations. Values obtained for the adult population are similar to those reported in three recent studies $(19,31,32)$. As observed previously $(20,27)$, cholestyramine treatment of hypercholesterolemic patients (Table 2) resulted in a marked elevation in plasma lathosterol levels and the lathosterol:cholesterol ratio above normal adult values, thus validating current methodology.

Deuterated water analysis (17) and glc assay of methyl sterols (33) have shown a diurnal cycle in cholesterol synthesis in adults, but it is not known whether lathosterol levels show periodicity. We found that plasma lathosterol levels may be an index of this phenomenon, plasma concentrations of lathosterol at $0830 \mathrm{~h}$ being greater than at $1700 \mathrm{~h}(p=0.04$, Table 2$)$.

Plasma lathosterol concentrations decreased from birth to $\mathrm{d} 4$ 
Table 1. Cholesterol, apoproteins, and lathosterol values in neonatal plasma [mean $\pm S D(n)]$

\begin{tabular}{|c|c|c|c|c|c|c|}
\hline & \multirow[b]{2}{*}{ Diet* } & \multirow[b]{2}{*}{ Cord } & \multirow[b]{2}{*}{ Day 4} & \multicolumn{3}{|c|}{$p$ values } \\
\hline & & & & $\begin{array}{c}\text { Group } \times \\
\text { time }\end{array}$ & Group & Time \\
\hline \multirow[t]{2}{*}{ Cholesterol $(\mathrm{mmol} / \mathrm{L})$} & $\mathrm{BM}$ & $1.63 \pm 0.21(6)$ & $2.22 \pm 0.21(6)$ & 0.4 & 0.05 & 0.0001 \\
\hline & $\mathrm{F}$ & $1.78 \pm 0.34(6)$ & $2.56 \pm 0.23(6)$ & & & \\
\hline \multirow[t]{2}{*}{ Apo AI $(g / L)$} & BM & $0.63 \pm 0.10(6)$ & $0.61 \pm 0.10(6)$ & 0.05 & & \\
\hline & $\mathrm{F}$ & $0.67 \pm 0.10(6)$ & $0.73 \pm 0.12(6)$ & & & \\
\hline \multirow[t]{2}{*}{ Apo B $(g / L)$} & BM & $0.18 \pm 0.03(6)$ & $0.31 \pm 0.07(6)$ & 0.8 & 0.8 & 0.0001 \\
\hline & $\mathrm{F}$ & $0.18 \pm 0.03(6)$ & $0.30 \pm 0.09(6)$ & & & \\
\hline \multirow[t]{2}{*}{ Lathosterol $(\mu \mathrm{mol} / \mathrm{L})$} & BM & $5.69 \pm 0.52(6)$ & $4.99 \pm 1.40(6)$ & 0.4 & 0.07 & 0.03 \\
\hline & $\mathrm{F}$ & $7.09 \pm 1.42(6)$ & $5.64 \pm 0.91(6)$ & & & \\
\hline Lathosterol/cholesterol $\left(10^{2} \times \mathrm{mmol}\right.$ & $\mathrm{BM}$ & $352 \pm 56(6)$ & $226 \pm 74(6)$ & 0.3 & 0.4 & 0.0003 \\
\hline lathosterol)/mol cholesterol & $\mathrm{F}$ & $404 \pm 97(6)$ & $220 \pm 24(6)$ & & & \\
\hline
\end{tabular}

* BM, breast milk; F, formula diet group.

Table 2. Plasma cholesterol and lathosterol values in adult reference populations [mean $\pm S D(n)$ and (range)]

\begin{tabular}{lccc}
\hline & \multicolumn{2}{c}{ Normal adult males } & \multicolumn{2}{c}{$\begin{array}{c}\text { Cholestyramine- } \\
\text { treated patients }\end{array}$} \\
\cline { 2 - 3 } Cholesterol $(\mathrm{mmol} / \mathrm{L})$ & $1700 \mathrm{~h}$ & $0830 \mathrm{~h}$ & $6.09 \pm 0.89(6)$ \\
& $4.85 \pm 0.33(6)$ & $4.85 \pm 0.52(6)$ & $(4.60-7.29)$ \\
Lathosterol $(\mu \mathrm{mol} / \mathrm{L})$ & $(4.58-5.33)$ & $(4.24-5.66)$ & $20.48 \pm 13.41(6) \dagger \ddagger$ \\
& $5.50 \pm 1.52(6)^{*} \dagger$ & $6.18 \pm 1.80(6)^{* \dagger}$ & $(10.47-43.47)$ \\
Lathosterol $/ \mathrm{cholesterol}\left(10^{2} \times \mathrm{mmol}\right.$ & $(3.39-7.24)$ & $(3.72-8.09)$ & $322.9 \pm 168.4(6) \dagger$ \\
lathosterol $) / \mathrm{mol}$ cholesterol & $112.5 \pm 26.0(6) \dagger \S \|$ & $129.4 \pm 42.2(6) \dagger \S \|$ & $(170-595)$ \\
\hline
\end{tabular}

* Normal adults, 1700 vs $0830 \mathrm{~h}, p=0.04$.

$\dagger$ Normal vs cholestyramine-treated adults, $p=0.02$.

$\ddagger$ Infants (cord or d 4) (see Table 1) vs cholestyramine-treated adults, $p=0.02$.

$\S$ Normal adults vs cord, (see Table 1) $p<0.0001$.

$\|$ Normal adults $v s \mathrm{~d} 4$ (see Table 1) infants, $p=0.002-0.0002$.

(Table 1), suggesting that the postnatal increase in plasma cholesterol levels is not coincident with enhanced cholesterol synthesis. Conceivably, the high levels of cholesterol may repress its synthesis via the LDL receptor pathway. The infants had not regained their birth weight by $4 \mathrm{~d}$ of age $[95.3 \pm 4.7$ (SD)\% of their birth weight]. A potential decrease in cholesterol synthesis at this time could be explained by limiting acetyl CoA levels for synthetic pathways due to negative energy balance during the establishment of enteral feeding in the first days after birth.

It is not known whether the newborn human has an established diurnal cycle of cholesterol synthesis by $4 \mathrm{~d}$ of age. To contrast values with adult levels, cord and neonatal blood samples were collected over a short time span and compared with the adult values at both 1700 and $0830 \mathrm{~h}$. Inasmuch as no differences between formula and breast milk groups were apparent, these data were pooled before being compared with adult values. No differences were found between neonatal and adult lathosterol concentrations at either adult extreme.

Plasma lathosterol:cholesterol ratios. Plasma lathosterol: cholesterol ratios were higher in cord versus d-4 samples (Table 1) and in neonatal versus adult samples (Table 2). This is likely due to the lower plasma cholesterol levels in the cord and neonatal samples, respectively. The plasma lathosterol: cholesterol ratio found in the cholestyramine-treated patients was higher than at both normal adult sampling times but comparable to those found in neonatal samples. The observation that precursor levels are the same, yet product is reduced, leads one to speculate that there is an increased demand for, or turnover of, plasma cholesterol in the rapidly growing neonate. The similar ratios in neonatal and cholestyramine-treated patient plasma is likely a reflection of both lower plasma cholesterol and lathosterol in the neonates.

Effect of breast-versus formula-feeding on plasma lathosterol levels. The plasma lathosterol concentrations of infants were not influenced by diet (Table 1). It was hypothesized that the lack of cholesterol in the formula would stimulate additional cholesterol synthesis and hence result in increased plasma lathosterol levels in the infants fed formula.

Plasma lathosterol as an indicator of cholesterol synthesis in the neonate. The validity of using plasma lathosterol as an indicator of cholesterol synthesis rates in the newborn has not been tested. At present, this would not be feasible, inasmuch as it would require a liver biopsy for the measurement of HMG CoA reductase activity. In addition, stable isotope methodology requires more extensive blood sampling and an interval of time to measure isotope incorporation and would thus be unsuitable for single point determinations, i.e. birth and $4 \mathrm{~d}$ of age. Finally, plasma mevalonate analysis would also require verificaiton for use in the neonate. In support of the lathosterol methodology, our data from preterm infants (34) show elevated plasma lathosterol levels coincident with administration of $10 \%$ Intralipid, which is predicted to be a stimulant of cholesterol synthesis (35).

Hypotheses to explain postnatal hypercholesterolemia. Onset of feeding. Although it seems that the cholesterol content of breast milk is not responsible for the postnatal elevation in plasma cholesterol levels, other dietary components may trigger this effect. Fat-feeding itself increases plasma cholesterol levels (36), and, theoretically, the reason for this could be increased cholesterol synthesis. Our data, however, indicate that there is no increase in the plasma lathosterol concentration, at least during the first $4 \mathrm{~d}$ of life. Breast milk contains saturated fatty acids, which, when compared with polyunsaturated fatty acids, are known to induce hypercholesterolemia in adults (37). Infant formulas, in contrast, are relatively enriched in polyunsaturated fatty acids and contain few long-chain saturated fatty acids. Manipulation of diet fat type in older infants (3-16 mo) shows that plasma cholesterol levels can be influenced by the degree of fat saturation in the same way as in adults (38). We, however, did not see different plasma lathosterol levels between breast-fed infants and those fed formula. Thus, it seems unlikely that the 
type of fat fed to infants had a significant effect on liver cholesterol synthesis in the first days of feeding.

Maturation of regulation of cholesterol homeostasis. LDL receptors are present on most cells and regulate uptake of intracellular cholesterol (39). Brown and Goldstein (39) have presented the hypothesis that there are relatively more LDL receptors at birth than in the adult (therefore, higher plasma cholesterol levels in the latter).

Supportive evidence for this theory was provided by Rudling and Peterson (10), who found greater in vitro LDL receptor binding in fetal (low plasma cholesterol levels) than postnatal (higher plasma cholesterol levels) tissue homogenates. Additionally, in our laboratory, ligand blotting has been recently used to demonstrate greater LDL receptor mass in fetal and neonatal than in adult liver membranes (40). Contrary to this, in humans, Andersen and Johansen (41) report that the number of LDL receptors in cultured cord blood lymphocytes is not different from that in adult control lymphocytes. One might suspect that this reflects an up-regulation that may occur during culture.

There is much evidence that the LDL receptor is fully mature and functional in both the fetus and the newborn (41-45). Most of this data is the result of the measurement of cholesterol synthesis in cultured cells and its ability to be stimulated and suppressed. This has been done with cord lymphocytes (40), amniotic fluid cells $(42,43)$, newborn foreskin cells $(42,44)$, and fetal hepatocytes (45). Given that the LDL receptor is already functional in the fetus, it seems plausible that changes in activity and/or mass of the receptor at birth may be the result of postnatal elevation of plasma cholesterol levels rather than its cause.

Involution of fetal zone of adrenal. The fetal zone of the human adrenal has a high requirement for cholesterol for production of many steroids (11). There is considerable evidence that the human fetal adrenal preferentially uses LDL cholesterol (11) acquired via the classical LDL receptor pathway (46) as the substrate for steroidogenesis. Theoretically, when the fetal zone of the adrenal regresses at birth, the demand for LDL cholesterol decreases and plasma levels increase (11). This theory can explain a number of observations: the increase in LDL at birth due to a rapid decrease in LDL clearance, the use of a unique lipoprotein (HDLe) in human fetal life (47) to substitute functionally for LDL in delivering cholesterol to cells, and elevated postnatal plasma cholesterol levels without increasing cholesterol synthesis.

Conclusions. Although the etiology of early postnatal elevation of plasma cholesterol levels in humans is unproven, data from this study suggest that increased lathosterol synthesis is not part of the mechanism. If, as in the adult, plasma lathosterol levels reflect cholesterol synthesis, our data dispel the hypothesis that initiation of a high-fat diet at birth stimulates cholesterol synthesis. It also seems that if the LDL receptor function is fully developed at birth, changes in receptor activity and/or mass may result from, rather than evoke, the elevation of plasma cholesterol levels in the first few days after birth. Theories forwarded by others describing the involution of the fetal zone of the adrenal are consistent with the results of this study. If not adrenal fetal zone atrophy, another mechanism independent of increased cholesterol synthesis likely accounts for the phenomenon of elevated plasma cholesterol levels immediately after birth.

Acknowledgments. The authors thank Dr. P. Jones for advice regarding the cholesterol synthesis diurnal rhythm, Dr. J. Frohlich and Ruth Greerson for providing the cholestyramine-treated adult samples, Murray MacKinnon of the Research Support Unit of British Columbia Children's Hospital for statistical assistance, and Dianne Arbuckle for sampling blood of adult control volunteers.

\section{REFERENCES}

1. Carroll K, Hamilton R 1973 Plasma cholesterol levels in suckling and weaned calves, lambs, pigs and colts. Lipids 8:635-640
2. Roberts D, Huff M, Carroll K 1979 Influence of plasma cholesterol concentra tions in suckling and weanling rabbits. Nutr Metab 23:476-486

3. Johansson M, Karlsson B 1982 Lipoprotein and lipid profiles in the blood serum of the fetal, neonatal and adult pig. Biol Neonate 42:127-137

4. Johansson M 1983 Lipoproteins and lipids in fetal, neonatal and adult rat serum. Biol Neonate 44:278-286

5. Potter J 1977 Perinatal plasma lipid concentrations. Aust N Z J Med 7:155160

6. Berenson GS, Frank GC. Hunter SM, Srinivasan SR, Voors AW, Webber LS 1982 Cardiovascular risk factors in children; should they concern the pediatrician. Am 3 Dis Child 136:855-862

7. Andersen GE 1985 Changes in plasma lipoproteins from first day to third week of human life. In: Detection and Treatment of Lipid and Lipoprotein Disorders of Childhood. Alan R Liss. New York, pp 87-91

8. McConathy WJ, Lane DM 1980 Studies on the apolipoproteins and lipoproteins of cord serum. Pediatr Res 14:757-761

9. Strobl W, Widhalm K, Kostner G, Pollak A 1983 Serum apolipoproteins and lipoprotein (a) during the first week of life. Acta Paediatr Scand 72:505-509

10. Rudling M, Peterson C $1985 \mathrm{LDL}$ receptors in bovine tissues assayed as the heparin-sensitive binding of ${ }^{125} \mathrm{I}$-labeled LDL in homogenates: relation between liver $\mathrm{LDL}$ receptor and serum cholesterol in the fetus and post term. Biochim Biophys Acta 836:96-104

11. Carr BR, Simpson ER 1981 Lipoprotein utilization and cholesterol synthesis by the human fetal adrenal gland. Endocr Rev 2:306-326

12. McNamara D, Quackenbush F, Rodwell V 1972 Regulation of hepatic 3hydroxy-3-methyl-glutaryl coenzyme A reductase. J Biol Chem 247:58055810

13. Boguslawski W, Wrobel J 1974 An inhibitor of sterol biosynthesis present in cow's milk. Nature 247:210-211

14. Carr BR, Simpson ER 1981 Synthesis of cholesterol in the human fetus: 3 hydroxy-3-methylglutaryl coenzyme A reductase activity of liver microsomes. J Clin Endocrinol Metab 53:810-812

15. Carr BR, Simpson ER 1982 Cholesterol synthesis in human fetal tissues. J Clin Endocrinol Metab 55:447-452

16. Kandutsch A, Taylor F 1985 Control of de novo cholesterol synthesis. In Strauss J, Meon K (eds) Lipoprotein and Cholesterol Metabolism in Steroidogenic Tissues. Stickley, Philadelphia, pp 1-7

17. Jones PJH, Schoeller DA 1990 Evidence for diurnal periodicity in human cholesterol synthesis. J Lipid Res 31:667-674

18. Parker TS, McNamara DJ, Brown CD, Kolb R, Ahrens EH, Alberts AW, Tobert J, Chen J, De Schepper PJ 1984 Plasma mevalonate as a measure of cholesterol synthesis in man. J Clin Invest 74:795-804

19. Farkkila MA, Miettinen TA 1988 Plasma lathosterol and campesterol in detection of ileal dysfunction. Scand J Gastroenterol 23:19-25

20. Bjorkhem I, Miettinen T, Reihner E, Ewerth S, Angelin B, Einarsson K 1987 Correlation between serum levels of some cholesterol precursors and activity of HMG-CoA reductase in human liver. J Lipid Res 28:1137-1143

21. Kempen HJM, Glatz JFC, Leuven JAG, van der Voort HA, Katan MB 1988 Serum lathosterol concentration is an indicator of whole-body cholesterol synthesis in humans. J Lipid Res 29:1149-1155

22. Lane DM, McConathy WJ 1986 Changes in the serum lipids and apolipoproteins in the first four weeks of life. Pediatr Res 20:332-337

23. Jensen RG 1989 Lipids in human milk: composition and fat soluble vitamins In: Lebenthal E (ed) Textbook of Gastroenterology and Nutrition in Infancy, 2nd Ed. Raven Press, New York, pp 157-208

24. Cress HR, Shaher RM, Laffin R, Karpowicz K 1977 Cord blood hyperlipoproteinemia and perinatal stress. Pediatr Res 11:19-23

25. Andersen G, Lous P, Friis-Hansen B 1979 Hyperlipoproteinemia in newborn infants. Acta Paediatr Scand 68:683-690

26. Boulton TJC 1979 Fetal, maternal and intrapartum factors and their effects on cord serum cholesterol and triglyceride. Aust $\mathrm{N} Z \mathrm{~J}$ Med 9:57-62

27. Gylling H, Vanhanen V, Miettinen TA 1989 Effects of acipimox and cholestyramine on serum lipoproteins, non-cholesterol sterols and cholesterol absorption and elimination. Eur J Clin Pharmacol 37:111-115

28. Cole JWL, Grizzle JE 1966 Applications of multivariate analysis to repeated measures experiments. Biometrics 22:810-828

29. Stozicky F, Slaby P, Volenikova L 1982 The pattern of major serum apoproteins during the early neonatal period. Acta Paediatr Scand 71:239-241

30. Darmady JM, Fosbrooke AS, Lloyd JK 1972 Prospective study of serum cholesterol levels during first year of life. Br Med J 2:685-688

31. Nikkila K, Miettinen TA 1988 Serum cholesterol precursors, cholestanol, and plant sterols in primary biliary cirrhosis. Scand J Gastroenterol 23:967-972

32. Miettinen TA, Tilvis RS, Kesaniemi YA 1990 Serum plant sterols and cholesterol precursors reflect cholesterol absorption and synthesis in volunteers of a randomly selected male population. Am J Epidemiol 131:20-31

33. Miettinen T 1982 Diurnal variation of cholesterol precursors squalene and methyl sterols in human plasma lipoproteins. J Lipid Res 23:466-473

34. Hamilton JJ, Phang M, Innis SM 1992 Elevation of plasma lathosterol, as an indicator of increased cholesterol synthesis, in preterm (23-32 wk gestation) infants given Intralipid. Pediatr Res 31:186-192

35. Griffin E, Breckenridge WC, Kuksis A. Bryan MH, Angel A 1979 Appearance and characterization of lipoprotein $X$ during continuous Intralipid infusions in the neonate. J Clin Invest 64:1703-1712

36. Bauer JE 1990 Increased serum and liver lipid mass and hepatic 3-hydroxy-3methylglutaryl CoA reductase activities in rabbits fed soy protein saturated fat diets. Artery 17:176-188 
37. Hegsted DM, McGandy RM, Myers ML, Stare RJ 1965 Quantitative effects of dietary fats on serum cholesterol in man. Am J Clin Nutr 17:281-295

38. Nestel PJ, Poyser A, Boulton TJC 1979 Changes in cholesterol metabolism in infants in response to dietary cholesterol and fat. Am J Clin Nutr 32:2177 2182

39. Brown M, Goldstein J 1986 A receptor-mediated pathway for cholesterol homeostasis. Science 232:34-47

40. Auestad N, Hamilton JJ, Innis SM 1991 Identification of the LDL (B/E) receptor during early development in rat liver using a sensitive ligand blotting assay. FASEB J 5:A950(abstr)

41. Andersen $G E$, Johansen $\mathrm{KB} 1980 \mathrm{LDL}$ receptor studies in term and pre-term infants: measurement of sterol synthesis in cord blood lymphocytes. Acta Paediatr Scand 69:577-580

42. Goldstein JL, Harrod MJE, Brown MS 1974 Homozygous familial hypercho- lesterolemia: specificity of the biochemical defect in cultured cells and feasibility of prenatal detection. Am J Hum Genet 26:199-206

43. Brown MS, Goldstein JL, Vandenberghe K, Fryns JP, Kovanen PT, Eeckels $\mathrm{R}$, van den Berghe H, Cassiman JJ 1978 Prenatal diagnosis of homozygous familial hypercholesterolemia. Lancet 1:526-529

44. Shakespeare V, Postle AD 1979 Regulation of cholesterol synthesis in skin fibroblasts derived from old people. Atherosclerosis 33:359-364

45. Carr BR, Simpson ER 1984 Cholesterol synthesis by human fetal hepatocytes: effect of lipoproteins. Am J Obstet Gynecol 150:551-557

46. Brown MS, Kovanen PT, Goldstein JL 1979 Receptor-mediated uptake of lipoprotein-cholesterol and its utilization for steroid synthesis in the adrenal cortex. Recent Prog Horm Res 35:215-257

47. Blum CB, Davis PA, Forte TM 1985 Elevated levels of apolipoprotein $\mathrm{E}$ in the high density lipoproteins of human blood cord plasma. J Lipid Res 26:755760 